\title{
Analysis of Macroeconomic Development Indicators of the Region
}

\author{
Nikolay S. Sadovin ${ }^{1}$, Tatiana N. Kokotkina ${ }^{1}$, Dmitri E. Bespalov ${ }^{1}$, Vladimir A. Borisov ${ }^{1} \&$ Evgeny I. \\ Tsaregorodsev ${ }^{1}$ \\ ${ }^{1}$ Mari State University, Yoshkar-Ola, Russia \\ Correspondence: Tsaregorodsev E. I., Mari State University, Lenina Sq., 1, Yoshkar-Ola, Republic of Mari El, \\ 424000, Russia. E-mail: evgts@yandex.ru
}

\author{
Received: February 21, 2015 Accepted: March 15, 2015 Online Published: April 29, 2015 \\ doi:10.5539/res.v7n8p206 \\ URL: http://dx.doi.org/10.5539/res.v7n8p206
}

\begin{abstract}
Regional aspect of forecasting in conditions of Russian economic environment plays particular role, since without the consideration of specific character of regions development no long-term national programs can be realized, as well as implementation of any social or economic reforms becomes impossible. The interrelation between economic advancement and social factors in the Republic of Mari El reviewed in this this article creates awareness of specific interrelation of gross regional product with considered factors and their influence on this index value.
\end{abstract}

Keywords: modelling, capital investments, price index, education level, budget

\section{Introduction}

Analysis and forecasting of socio-economic development are starting points of regional development management performance. On the basis of sound forecast aims of socio-economic development of region are defined, economic complex development concerned policy events and priorities are specified. And as a consequence of that, efficiency of regional development management largely determined by quality of these forecasts. Regional aspect of forecasting in conditions of Russian economic environment plays particular role, since without the consideration of specific character of regions development no long-term national programs can be realized, as well as implementation of any social or economic reforms becomes impossible.

Considering interrelation between population and economic development, it is necessary to refer to population growth economy, which studies the impact of changes in population size on economic growth dynamics, together with consideration of belonged models, which are founded on one basic equation, which describes the influence of demographic variable on economy. Problem of the relationship of social and economic factors were considered by Russian authors (Dagbaev, 2015; May, 2015; Hohlova 2006; Sharaev, 2006), and and foreign authors (Barro \& Sala-i-Martin, 2004; Weber, 2010; Preston, Heuveline, \& Guillot, 2000; Miles, 1997).

Models of population growth economy continue being designed and form significant part of researches of this guideline (Ilyin, 2014; Hohlova, 2007). Macro-economic problems of the Republic of Mari El studied in Mary State University (Tsaregorodtsev \& Borisov, 2014; Tsaregorodtsev \& Bespalov, 2014; Sadovin \& Kokotkina, 2014). Development of the approach considering economic progress in conjunction with population variable is solely due to practical reasons: relative simplicity of interpretation of obtained results and possibility of direct use of them in forecasting and development policy design applications. These models include modern single-circuit models, which are used for the rating of influence of population growth dynamics and it's components on different aspects of economic progress.

\section{Method}

Among models focused on the impact of demographic factors on the "sustained level" of labour productivity separately stand out Barro's models (Barro, \& Sala-i-Martin, 2004). Barro's works were reviewed in the Theory economic growth (Sharaev, 2006). Demographic factor in such models is represented by one or two exogenous variables (total fertility rate, life expectancy at birth), according to nature of evaluation expecting the long-term maintenance of existent age fertility and mortality rates. Other factors of "sustained level" of labour productivity included in Barro's model are: government intervention in the economy, social infrastructure facilities, price setting, political stability, social tensions and so on. 
Barro substantiated assumptions regarding indexes of model's parameters. So, the coefficient of the variable of GDP per head is less than zero in accordance with neoclassic hypothesis of tendency of economy to sustained state, the coefficient of the variable of education enrollment coverage is bigger than zero, since these indicators reflect dynamics of human capital value - the key factor of economic growth; coefficient of the variable of government expenses is less than zero, since such expenses decrease rate of savings (education and defense expenditures are excluded from total amount of government expenses, as they are considered as public investments and statistically included in the gross domestic investments); coefficients of the variable of revolutions and willful killing are less than zero, since number of them is considered as indicator of political instability, negatively affecting property rights and private investments; coefficient of the variable of divergence of government investments to the capital assets is less than zero, since public expenditures in GDP can be just slightly changed in each country over a period of time (therefore public and private capital have the same rate of depreciation), which causes deceleration of the capital renewal processes after decreasing (increasing) of public investments ratio (negatively affects the efficiency of private investments).

Broadening of R. Barro's model at the expense of demographic dimensions didn't cause major differences of initial parameters of regression equation, however the precision of estimation was increased $\left(R^{2}\right.$ was increased by 0.15 ). Meanwhile, two inserted demographic dimensions appeared statistically significant. Generally, the rate of population growth directly reflects the impact of demographic factor; however, this has weak negative impact; both density and size of population reflect the effect of production scale and possibility of new technologies adoption, which causes positive impact.

Design of models, estimating both impact of demographic variables on the "stable level" of labour productivity and features of advancement to this level, is connected with decomposition of demographic factor on the impact of mortality and fertility, past and current. Subsequent Barro's works outlined in the Economic Growth (Barro \& Sala-i-Martin, 2004).

On the basis of Barro's ideas it was decided to apply his model in this article, but not for the number of countries, but for certain region of Russia, The Republic of Mari El. It's small republic in the Russian Federation, located in the temperate climate zone. The population of the Republic is approximately 700 thousand people, in the gross regional product main primary economic activities are: manufacturing activities, agriculture, hunting and forestry, wholesale and retail trade, vehicle, motorcycle and consumer goods repairs, construction, public administration and military defense, social insurance, as well as transportation and communications. In the volume of fixed capital investments own funds make slightly more than $25 \%$, remains-obtained funds. The Republic has high proportion of citizens of employable age, and as a result of this structural advantage, the level of economic activity of the Republic's population is comparable to the national average.

\section{Results}

Data required for the analysis of the Republic characteristics has been taken from past 14 years (2000-2013). The following variables were used as main features of the model:

1) The Gross regional product per head $(\mathrm{Y} / \mathrm{N})$;

2) The proportion of people receiving secondary education to population ratio (SecEnr);

3) The proportion of people receiving higher education to population ratio (HighEnr);

4) Expenses ratio of consolidated budget in GRP (Gcons/Y);

5) Consumer price index (Inflatn);

6) Fixed assets investments ratio in GRP (PPIDev);

7) Life expectancy at birth (e0);

8) Number of grave and gravest crimes per head (Assass).

GRP in this model is endogenous variable per head $(\mathrm{Y} / \mathrm{N})$, remain indicators-exogenous. STATISTICA 6.0 package was used for the analysis purposes, as this program is one of simplest, but at the same time very efficient for data processing and obtaining results in analytic and graphic representation. Indicators taken for the Barro's model construction are reproduced in the Table 1. 
Table 1. Barro's model indicators dynamics

\begin{tabular}{lllllllll}
\hline & LnY/N & SecEnr & HighEnr & Gcons/Y & Inflatn & PPIDev & lne $_{0}$ & Assass \\
\hline 2000 & 9.62343 & 0.015057 & 0.030249 & 0.178594 & 1.211 & 0.151733 & 4.168833 & 0.016802 \\
2001 & 9.928307 & 0.015965 & 0.033419 & 0.214083 & 1.182 & 0.128334 & 4.161847 & 0.015773 \\
2002 & 10.1028 & 0.01774 & 0.037937 & 0.27379 & 1.149 & 0.164256 & 4.195697 & 0.009303 \\
2003 & 10.36525 & 0.01899 & 0.039081 & 0.238741 & 1.121 & 0.189043 & 4.15638 & 0.006876 \\
2004 & 10.64116 & 0.019255 & 0.039479 & 0.24368 & 1.116 & 0.194943 & 4.150252 & 0.007049 \\
2005 & 10.75143 & 0.019808 & 0.040312 & 0.244855 & 1.092 & 0.230663 & 4.151512 & 0.008703 \\
2006 & 11.02802 & 0.020661 & 0.042164 & 0.242109 & 1.074 & 0.244045 & 4.17408 & 0.008856 \\
2007 & 11.26597 & 0.020518 & 0.043441 & 0.248535 & 1.133 & 0.311634 & 4.194793 & 0.007894 \\
2008 & 11.44814 & 0.019198 & 0.043942 & 0.253595 & 1.139 & 0.324813 & 4.199305 & 0.00823 \\
2009 & 11.50368 & 0.017569 & 0.043565 & 0.254747 & 1.085 & 0.238967 & 4.208566 & 0.006015 \\
2010 & 11.67938 & 0.017 & 0.043 & 0.250816 & 1.115 & 0.270766 & 4.20916 & 0.003895 \\
2011 & 11.85114 & 0.0161 & 0.0401 & 0.234822 & 1.06 & 0.275995 & 4.22391 & 0.003501 \\
2012 & 12.04408 & 0.016 & 0.0368 & 0.208562 & 1.063 & 0.269192 & 4.234107 & 0.002787 \\
2013 & 12.09937 & 0.0145 & 0.033 & 0.215686 & 1.065 & 0.364507 & 4.238445 & 0.002283 \\
\hline
\end{tabular}

Using the data, represented in the Table 1, the regression analysis of the impact of the model's exogenous indicators on the forming process of the endogenous variable has been performed $\ln (\mathrm{Y} / \mathrm{N})$. Obtained results are shown in the Figures $1 \& 2$ :

\begin{tabular}{||l|r|}
\hline \multirow{2}{*}{ Statistic } & Summary Statistics; DV: LnY/N (Spreadsheet2) \\
\cline { 2 - 2 } & \multicolumn{1}{|c|}{ Value } \\
\hline Multiple R & 0,990376542 \\
\hline Multiple R? & 0,980845695 \\
\hline Adjusted R? & 0,958499005 \\
\hline F(7,6) & 43,8922147 \\
\hline P & 0,0000978570679 \\
\hline Std. Err. of Estimate & 0,164155363 \\
\hline & \\
& \\
&
\end{tabular}

Figure 1. Results of regression analysis

As seen in Figure 1 the coefficient of multiple correlation, defining correlation ratio between dependent variable and independent indicators, is equal to 0.9904 and it is quite high. Obtained model can be called reliable, because coefficient of determination is very close to unity $\left(R^{2}=0.9808\right)$, at the same time the standard error of the estimation of equation is quite small and equals to 0.1642 . Coefficient $\mathrm{R}^{2}$ represents that drawn regression explains more than $98 \%$ of spread of values of variable $\ln (\mathrm{Y} / \mathrm{N})$ about a mean. If we pay an attention to the value of F- criterion $\left(\mathrm{F}_{\mathrm{tab}}=43.8922>\mathrm{F}_{\mathrm{cr}}=4.2067\right)$, we can see and say, that the regression equation is significant. 


\begin{tabular}{|c|c|c|c|c|c|c|}
\hline \multirow[b]{2}{*}{$\mathrm{N}=14$} & \multicolumn{6}{|c|}{$\begin{array}{l}\text { Regression Summary for Dependent Variable: LnY/N (Spreadsheet2 } \\
R=, 99037654 \text { R?= ,98084569 Adjusted R?= ,95849901 } \\
F(7,6)=43,892 p<, 00010 \text { Std. Error of estimate: ,16416 }\end{array}$} \\
\hline & $\mathbf{b}^{\star}$ & \begin{tabular}{|c|}
$\begin{array}{c}\text { Std.Err. } \\
\text { of } b^{*}\end{array}$ \\
\end{tabular} & b & $\begin{array}{c}\begin{array}{c}\text { Std.Err. } \\
\text { of } b\end{array} \\
\end{array}$ & $t(6)$ & p-value \\
\hline Intercept & & & 2,682 & 17,50064 & 0,15327 & 0,883213 \\
\hline SecEnr & $-0,281323$ & 0,174695 & $-110,170$ & 68,41292 & $-1,61037$ & 0,158442 \\
\hline HighEnr & 0,489244 & 0,156718 & 90,161 & 28,88080 & 3,12182 & 0,020537 \\
\hline Gcons $/ Y$ & $-0,257876$ & 0,116353 & $-8,599$ & 3,88007 & $-2,21632$ & 0,068544 \\
\hline Inflatn & $-0,305708$ & 0,125643 & $-5,277$ & 2,16895 & $-2,43315$ & 0,050943 \\
\hline PPIDev & 0,385580 & 0,117342 & 4,512 & 1,37305 & 3,28595 & 0,016698 \\
\hline Ine0 & 0,123935 & 0,150701 & 3,290 & 4,00052 & 0,82239 & 0,442302 \\
\hline Assass & $-0,131610$ & 0,159399 & $-24,540$ & 29,72178 & $-0,82566$ & 0,440582 \\
\hline
\end{tabular}

Figure 2. Results of regression analysis

According to the data given in the Figure 2, we can write the following regression equation:

$$
\begin{aligned}
\ln \frac{\mathrm{Y}}{\mathrm{N}} & =2.682-110.17 \mathrm{SecEnr}+90.161 \mathrm{HighEnr}-8.599 \frac{\text { Gcons }}{\mathrm{Y}}- \\
& -5.277 \text { Inflatn + 4.512 PPIDev + 3.29 } \operatorname{lne}_{0}-24.54 \text { Assass. }
\end{aligned}
$$

Factors HighEnr, PPIDev, lne0 have positive impact on GRP level, i.e. increase of their value will lead to the growth of the gross regional product value per head. Remain independent variables negatively impact the value of variable $\ln (\mathrm{Y} / \mathrm{N})$, i.e. increase of their values will lead to the reduction of the GRP.

Coefficients of variables of education enrollment coverage in the obtained model are: $90.161>0-$ of the variable of proportion of people receiving higher education; $-110.17<0$ - of the variable of proportion of people receiving secondary education (according to Barro these indicators are bigger than zero, as they reflect dynamics of the human capital value - key factor of economic growth). Coefficient of variable of government expenses is equal to-8.599 $<0$ (such expenses decrease rate of savings). Coefficient of variable defining crime rate is equal to-24.540 $<0$ (approaches as an indicator of political instability having negative impact on property rights and private investments).

In addition to that, according to the data provided by Figure 2, we can write the equation of influence of factor variables on the value of variable $\ln (\mathrm{Y} / \mathrm{N})$ as follows:

$$
\begin{aligned}
t_{\ln \frac{\mathrm{Y}}{\mathrm{N}}=} & -0.281323 \mathrm{SecEnr}+0.489244 \text { HighEnr }-0.257876 \frac{\text { Gcons }}{\mathrm{Y}}-0.305708 \text { Inflatn }+ \\
& +0.38558 \text { PPIDev }+0.123935 \operatorname{lne}_{0}-0.13161 \text { Assass. }
\end{aligned}
$$

The greatest positive impact on GRP level has the share of people with higher education, the greatest negative impact-level of consumer price index.

According to Student's t-criterion it's possible to check the significance of indicators forming a part of the regression equation $\left(t_{c r}=2.446912\right)$, then only indicators of share of fixed assets investments and share of people receiving higher education remain significant, others do not.

Using stepwise regression with the exception the following data was obtained (Figures 3, 4). 


\begin{tabular}{||l|r|}
\hline \multirow{2}{*}{ Statistic } & Summary Statistics; DV: LnY/N (Spreadsheet' \\
\cline { 2 - 2 } & \multicolumn{1}{|c|}{ Value } \\
\hline Multiple R & 0,988328601 \\
\hline Multiple R? & 0,976793423 \\
\hline Adjusted R? & 0,962289312 \\
\hline $\mathrm{F}(5,8)$ & 67,3459708 \\
\hline $\mathrm{p}$ & 0,0000254454994 \\
\hline Std.Err. of Estimate & 0,156479717 \\
& \\
\hline
\end{tabular}

Figure 3. Results of regression analysis

The index of multiple determinations defines that $97.68 \%$ of value of gross regional product per head depends on factor variables. $\mathrm{F}_{\mathrm{tab}}=67.346>\mathrm{F}_{\mathrm{cr}}=3.687$, from which it can be concluded that regression equation is significant. Standard error of the estimation of equation is quite small and equals to 0.1565 . To ensure the confident use of regression analysis results for further operations, you need to check the model's adequacy. Adequacy analysis is based on the analysis of residuals. Residuals correspond the difference between observed values and model ones, i.e. values, evaluated by the model with estimated parameters.

Normal probability of residuals can be also considered as model's adequacy criterion. Histogram of the distribution of residuals is provided in the Figure 4. Drawn model is adequate, since histogram is close to the normal plot.

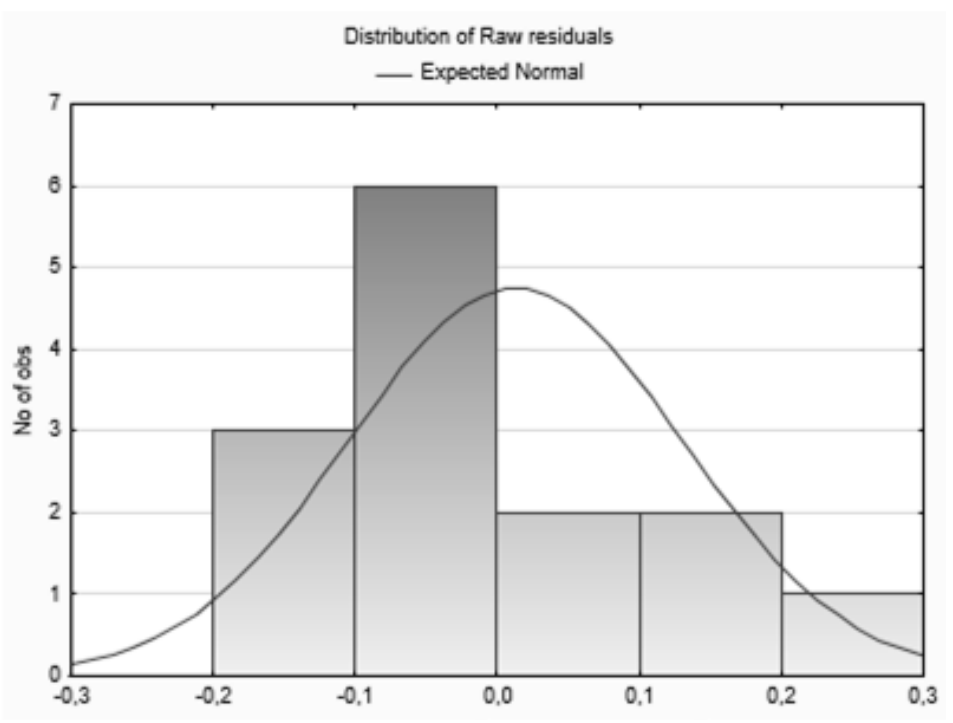

Figure 4. Histogram of the distribution of residuals 


\begin{tabular}{|c|c|c|c|c|c|c|}
\hline \multirow[b]{2}{*}{$N=14$} & \multicolumn{6}{|c|}{$\begin{array}{l}\text { Regression Summary for Dependent Variable: LnY/N (Spreadsheet2) } \\
\mathrm{R}=, 98832860 \mathrm{R} ?=, 97679342 \text { Adjusted R?= } 96228931 \\
\mathrm{~F}(5,8)=67,346 \mathrm{p}<, 00000 \text { Std. Error of estimate: }, 15648\end{array}$} \\
\hline & $\mathbf{b}^{*}$ & $\begin{array}{c}\text { Std.Err. } \\
\text { of } b^{*}\end{array}$ & b & $\begin{array}{c}\text { Std.Err. } \\
\text { of } b\end{array}$ & $t(8)$ & p-value \\
\hline Intercept & & & 18,103 & 1,61805 & 11,18794 & 0,000004 \\
\hline SecEnr & $-0,438089$ & 0,086770 & $-171,562$ & 33,98017 & $-5,04888$ & 0,000991 \\
\hline HighEnr & 0,557184 & 0,136075 & 102,681 & 25,07665 & 4,09469 & 0,003463 \\
\hline Gcons/Y & $-0,214092$ & 0,103834 & $-7,139$ & 3,46259 & $-2,06186$ & 0,073148 \\
\hline Inflatn & $-0,400866$ & 0,070629 & $-6,920$ & 1,21926 & $-5,67566$ & 0,000467 \\
\hline PPIDev & 0,480435 & 0,074856 & 5,622 & 0,87590 & 6,41817 & 0,000205 \\
\hline
\end{tabular}

Figure 5. Results of regression analysis

According to the data given in the Figure 5, we can write the following regression equation:

$$
\begin{aligned}
\ln \frac{\mathrm{Y}}{\mathrm{N}}= & 18.103-171.562 \mathrm{Sec} \text { Enr }+102.681 \mathrm{HighEnr}-7.139 \mathrm{Gcons} / \mathrm{Y}-6.920 \text { Inflatn }+ \\
& +5.622 \mathrm{PPIDev} .
\end{aligned}
$$

Factors HighEnr, PPIDev have positive impact on the gross regional product level, thereby increase of their values will lead to the growth of the GRP per head. Factors SecEnr, Gcons/Y and Inflatn negatively impact the value of resultant variable, i.e. increase of their values will lead to the reduction of the GRP.

Equation of an influence of factor variables on the value of resultant variable is written as follows:

$$
\begin{aligned}
t_{\ln \frac{\mathrm{Y}}{\mathrm{N}}}=- & 0.438089 \mathrm{SecEnr}+0.557184 \mathrm{Hi} \mathrm{ghEnr}-0.214092 \mathrm{Gcons} / \mathrm{Y}- \\
& -0.400866 \text { Inflatn }+0.480435 \mathrm{PPI} \text { Dev. }
\end{aligned}
$$

Share of the people receiving higher education to population ratio- 0.5572 , has the greatest impact on the value of gross regional product per head in the Republic of Mari El, share of consolidated budget expenses in GRP - the lowest.

Using Student's t-criterion you can check the significance of indicators forming a part of regression equation $\left(t_{\mathrm{cr}}=2.306\right)$, despite that the indicator of the share of consolidated budget expenses in GRP is insignificant.

Using stepwise regression with the exception the following results were obtained (Figure 6-8):

\begin{tabular}{||l|r|}
\hline \multirow{2}{*}{ Statistic } & Summary Statistics; DV: LnY/N (Spreadsheet2) \\
\cline { 2 - 2 } & \multicolumn{1}{|c|}{ Value } \\
\hline Multiple R & 0,982069857 \\
\hline Multiple R? & 0,964461204 \\
\hline Adjusted R? & 0,948666184 \\
\hline F(4,9) & 61,0610928 \\
\hline p & 0,00000160586706 \\
\hline Std.Err. of Estimate & 0,182569236 \\
& \\
& \\
& \\
\hline
\end{tabular}

Figure 6. Results of regression analysis

The $96.44 \%$ of value of gross regional product per head depends on factor variables. $F_{\mathrm{tab}}=61.061>\mathrm{F}_{\mathrm{cr}}=3.633$, from which it can be concluded that regression equation is significant. Standard error of the estimation of equation is quite small and equals to 0.1826 . Drawn model is adequate, since histogram is close to the normal plot (Figure 7). 


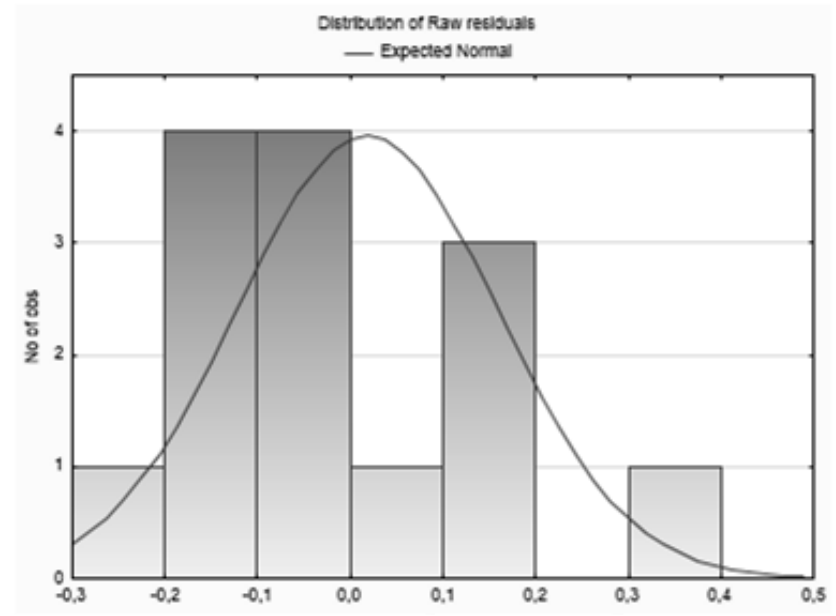

Figure 7. Histogram of the distribution of residuals

\begin{tabular}{|c|c|c|c|c|c|c|}
\hline \multirow[b]{2}{*}{$\mathrm{N}=14$} & \multicolumn{6}{|c|}{$\begin{array}{l}\text { Regression Summary for Dependent Variable: LnY/N (Spreadsheet2) } \\
R=, 98206986 \mathrm{R} ?=, 96446120 \text { Adjusted } R ?=, 94866618 \\
F(4,9)=61,061 \mathrm{p}<, 00000 \text { Std. Error of estimate: }, 18257\end{array}$} \\
\hline & $\mathbf{b}^{\star}$ & $\begin{array}{c}\text { Std.Err. } \\
\text { of } b^{*}\end{array}$ & b & $\begin{array}{c}\text { Std.Err. } \\
\text { of } b\end{array}$ & $t(9)$ & p-value \\
\hline Intercept & & & 17,527 & 1,85952 & 9,42561 & 0,000006 \\
\hline SecEnr & $-0,426706$ & 0,101031 & $-167,104$ & 39,56528 & $-4,22350$ & 0,002228 \\
\hline HighEnr & 0,356077 & 0,110704 & 65,620 & 20,40119 & 3,21648 & 0,010549 \\
\hline Inflatn & $-0,393372$ & 0,082296 & $-6,791$ & 1,42066 & $-4,77999$ & 0,001001 \\
\hline PPIDev & 0,523461 & 0,083874 & 6,125 & 0,98143 & 6,24105 & 0,000151 \\
\hline
\end{tabular}

Figure 8. Results of regression analysis

According to the obtained results we can write the following regression equation:

$$
\ln \frac{\mathrm{Y}}{\mathrm{N}}=17.527-167.104 \mathrm{Sec} \mathrm{Enr}+65.62 \mathrm{HighEnr}-6.791 \text { Inflatn + 6.125PPIDev. }
$$

Increase of HighEnr, PPIDev factor values will lead to the growth of the GRP per head. Increase of SecEnr, Inflatn factor values will lead to the reduction of the GRP level.

Equation of an influence of factor variables on the value of resultant variable is written as follows:

$$
t_{\ln \frac{\mathrm{Y}}{\mathrm{N}}}=-0.426706 \mathrm{SecEnr}+0.356077 \text { HighEnr - 0.393372Inflatn + 0.523461PPIDev. }
$$

Share of the fixed assets investment in GRP- 0.523461 has the greatest impact on the value of gross regional product per head in the Republic of Mari El, share of people receiving higher education to population ratio - the lowest.

According to the Student's t-test $\left(t_{\mathrm{cr}}=2.262\right)$ all indicators of the equation are significant.

\section{Conclusion}

Thus, the Barro's model was drawn for the Republic of Mari El, which shows that the indicator of share of fixed assets investments in GRP has the greatest impact on the level of the Republic's gross regional product.

Considering all stages of modelling it's easy to see that indicators of share of people receiving higher education to population ratio as well as indicator of share of fixed assets investments in all models had statistical significance and huge positive impact on the Republic's GRP. But factors with the negative sign in front of variable have negative impact on considered indicator, which shouldn't be underestimated. Therefore we can affirm that the assumption of dependence of GRP on these factors is confirmed. 


\section{Acknowledgment}

This article was prepared under a grant of the Russian Humanitarian Foundation (project "Interactive complex of simulation models of economy branches development of Mari El Republic" \# 15-12-12003).

\section{References}

Barro, R., \& Sala-i-Martin, X. (2004). Economic Growth (2nd ed.). Cambridge, Massachusetts. London, England: MIT Press.

Dagbaev, E. D. (2015). Regions and the new east policy Russia. POLIS. Political Studies, 1, 151-157.

Hohlova, O. A. (2006). Regional diagnostics as methodological basis of statistical studies regional economy. Statistical Issues, 9, 52-58.

Hohlova, O. A. (2007). Prediction main indicators of economic development of regions. Statistical Issues, 2 , 50-57.

Ilyin, V. (2014). Budget crisis as a reflection of the regions ineffectiveness obsolete economic model. Economist, $12,12-20$.

May, V. (2015). Socio-economic policy of Russia in 2014: Access to new frontiers? Problems of Economics, 2, 5-31.

Miles, D. (1997). Economic Implications of European Demographic Change. Economic Outlook, 22(1), 18-21. http://dx.doi.org/10.1111/1468-0319.00099

Preston, S., Heuveline, P., \& Guillot, M. (2000). Demography: Measuring and Modeling Population Processes. New York, NY: Wiley-Blackwell.

Sadovin, N. S., \& Kokotkina, T. N. (2014). Analysis of human potential influence on housing market of the Republic of Mari El. Proceedings of the free economic society of Russia, 189, 363-368.

Sharaev, U. V. (2006). Theory economic growth. Moscow Higher school of Economics.

Tsaregorodtsev, E. I., \& Bespalov, D. E. (2014). Impact of inflation on wage dynamics. Vestnik of Mari State University, Yoshkar-Ola, 1(14), 95-99.

Tsaregorodtsev, E. I., \& Borisov, V. A. (2014). Methods of evaluating the investment performance of the Republic of Mari El. Vestnik of Mari State University, Yoshkar-Ola, 2(14), 93-97.

Weber, L. (2010). Demographic Change and Economic Growth. Springer-Verlag Berlin Heidelberg. http://dx.doi.org/10.1007/978-3-7908-2590-9

\section{Copyrights}

Copyright for this article is retained by the author(s), with first publication rights granted to the journal.

This is an open-access article distributed under the terms and conditions of the Creative Commons Attribution license (http://creativecommons.org/licenses/by/3.0/). 